\title{
Orthogonal optimization of horizontal well fracturing method
}

\author{
Chi Dong*, Kao-Ping Song, Xiao-Qi Chen
}

Key Laboratory of Ministry of China on Enhanced Oil and Gas Recovery, Da Qing, China;

*Corresponding Author: dongchidongchi@163.com

Received 18 May 2010; revised 29 June 2010; accepted 5 July 2010.

\begin{abstract}
In many applications, streamline simulation shows particular advantages over finite-difference simulation. By the advantages of streamline simulation such as its ability to display paths of fluid flow and acceleration factor in simulation, the description of flooding process gets more visual effect. The communication between wells and flooding area has been represented appropriately. In low permeability reservoirs horizontal wells have been applied to stimulate. And some horizontal wells have been fractured. But different fracturing methods are followed by different effects. Through streamline simulation this paper presents that the fractures improve both the productivity of horizontal well and the efficiency of the flooding unit. And the syntagmatic relation of distance between artificial fractures, fracture length and fracture conductivity has been given by orthogonal experiment. This method has been applied to the D160 reservoir in Daqing Oilfield. The production history of this reservoir is about 2 years. The reservoir is maintained above bubble point so the simulation meets the slight compressibility assumption. New horizontal wells are fractured followed from this rule.
\end{abstract}

Keywords: Streamline Simulation; Horizontal Well; Optimization

\section{INTRODUCTION}

Using horizontal wells to stimulate and enhance oil recovery, has been applied widely all over the world. It is necessary to use horizontal wells to develop low permeability reservoirs. In the long process of practice, it was discovered that the advantages of horizontal well would not be made full use of when only the horizontal well drilling techniques not the combination with the actual development conditions has be paid attention to. In low permeability reservoirs the horizontal wells need to be fractured to stimulate. As the increase of the length of horizontal section, the number of artificial fractures should be increased too. And the syntagmatic relation of distance between fractures, fracture length and fracture conductivity is necessary to be optimized.

As the application of high-resolution geologic models in simulations, more attention had been paid to the use of simulation in oil field development. Finite difference method which applied widely cannot meet the needs such as high computational efficiency and being visually appealing. So the 3D streamline simulation approach has been applied to simulation as complementary to finite difference simulation techniques [1-4].

Streamline simulation is in the advanced and matured stage in slightly compressible system. It calculates the saturation via 1D streamline instead of saturation field [5]. Both computational efficiency and matching high resolution geologic models becomes possible. Not like the unity of the saturation in finite difference grid cell, streamline simulation provides several values of the saturation in one grid cell, then the fineness of the solution gets elevated.

Taking advantage of streamline simulation's particular capability, the syntagmatic relation of distance between artificial fractures, fracture length and fracture conductivity has been optimized by orthogonal experiment method.

\section{STREAMLINE SIMULATION THEORY}

\subsection{Velocity Field Solution and Streamline Tracing}

The streamline model is a model with the assumptions as follows: 1) Considering the effects of gravity and capillary; 2) There are oil phase and water phase in the reservoir; 3) The fluid flow in the reservoir is incompressi- 
ble; 4)The fluid flow obeys Darcy's Law; 5)The flow is under an isothermal condition. On the basis of these assumptions, and utilizing the continuity equation and flow equation, the pressure equation of streamline model can be established as follows:

$$
\nabla \cdot\left[\lambda_{\mathrm{t}}\left(\nabla P_{\mathrm{w}}-\gamma \nabla D\right)\right]+q_{\mathrm{v}}+\nabla \cdot\left[\lambda_{0} \nabla P_{\text {cow }}\right]=0
$$

where $\lambda_{0}, \lambda_{\mathrm{w}}$ are, respectively, mobility of oil and water, $\mu \mathrm{m}^{2} / \mathrm{Pa} \cdot \mathrm{s} ; \lambda_{\mathrm{t}}$ is total mobility, $\mu \mathrm{m}^{2} / \mathrm{Pa} \cdot \mathrm{s} ; \gamma_{\mathrm{o}}, \gamma_{\mathrm{w}}$ are, respectively, gravities of oil and water, dimensionless; $q_{\mathrm{vo}}$, $q_{\mathrm{vw}}$ are volume flow rate of producer and injector, $\mathrm{m}^{3} / \mathrm{s}$; $q_{\mathrm{v}}$ is the total flow rate of injection or production wells, $\mathrm{m}^{3} / \mathrm{s} ; D$ is the depth from the reference level, its direction is the same to gravity acceleration, $\mathrm{m} ; p_{\text {cow }}$ is the capillary force between oil phase and water phase, $\mathrm{Pa}$.

Eq. 1 can be solved by finite difference method. And the pressure distribution, i.e. pressure field, can be derived.

According to the pressure field, streamline tracing is implemented by using Pollock method which is defined with the following assumptions: the velocity field in a grid cell as a linear interpolation, and the velocity in each direction is only a function of the coordinate in that direction.

In a $2 \mathrm{D}$ grid system, with the pressure at the face, the potential at the face of the grid cell can be calculated. Then the velocity in each direction is derived, the TOF can be calculated also. The face at which the streamline exits is the one corresponding to the minimum positive exit time. The exit point will be the entry point of the adjacent grid cell, repeating this calculation process until the result converges to the grid cell which a production well is in. Connecting the exit points in chronological, an integrated streamline can be derived.

In a $3 \mathrm{D}$ system, the exit points can be obtained by utilizing Pollock method to calculate the values in the z-direction. By connecting these points, production and injection wells, the streamline can be derived.

The advantages of this method: being analytical; and it constructs a velocity field that satisfies the flux conservation condition.

\subsection{Saturation Field}

After the pressure filed is solved and the streamlines are traced by utilizing finite difference method, the next step is to solve the saturation along the streamlines by introducing the time-of-flight concept. The time-of-flight is defined as the time required for a particle to travel a distance along the streamline,

$$
\tau(s)=\int_{0}^{x} \frac{1}{\left|u_{t}(\varsigma)\right|} d \varsigma
$$

In streamline tracing, the time for streamlines across each grid cell, $\Delta t_{e, i}$, can be calculated using Pollock method. The time of flight can be expressed as follow:

$$
\tau=\sum_{i=1}^{n \text { blocks }} \Delta t_{e, i}
$$

where nblocks designates the number of grid cells when a particle travel a distance as $\mathrm{s} ; \Delta t_{e, i}$ is the time for a particle to travel through the i'th cell, s.

A. Distribution of volumetric flux of streamline. Tracing streamline from the cell of injection well to the cell of production well. For a grid cell with source or sink, as the streamline is not linear in segments, the streamline generalizes from the face of the grid cell instead of generalizing from the centre of the grid cell.

For simplicity, distribution of flux is based on changing the number of streamlines with different flow rate of injection well, and the volumetric flux along each streamline is constant. The higher injection flow rate, the more streamlines. Similarly, much more streamlines can be traced in a high flow rate region.

In grid cell $(i, j, k)$ with a source, the volumetric flux at the interface $(i \pm 1 / 2, j, k)$ of grid cell $(i, j, k)$ and grid cell $(i$ $\pm 1, j, k)$ is $Q_{i \pm 1 / 2, j, k}$. The volumetric flux along each streamline is $q_{s l i \pm 1 / 2, j, k}$ at the interface $(i \pm 1 / 2, j, k)$. The number of streamlines generalized from this face is $n_{i \pm}$ $1 / 2, j, k$ can be expressed as follow:

$$
n_{i \pm 1 / 2, j, k}=Q_{i \pm 1 / 2, j, k} / q_{s l i \pm 1 / 2, j, k}
$$

where $Q_{i \pm 1 / 2, j, k}$ is given as:

$$
Q_{i \pm 1 / 2, j, k}=T X_{i \pm 1 / 2, j, k}\left(P_{i, j, k}-P_{i \pm 1, j, k}\right)
$$

where $T X_{i \pm 1 / 2, j, k}$ represents the transmissibility in the $\mathrm{x}$-direction of oil phase and water phase between the grid cell $(i \pm 1, j, k)$ and the grid cell $(i, j, k) ; P_{i, j, k}$ is the pressure in the grid cell $(i, j, k)$.

Similarly, the number of streamlines on other faces can be obtained.

B. Establishing the saturation equation in streamline model. Considering capillary effect, the fluid flow equation can be expressed as follow:

$$
\overline{v_{\mathrm{i}}}=-\lambda_{\mathrm{t}}\left(\nabla P_{\mathrm{w}}-\gamma \nabla D\right)-\lambda_{0} \nabla P_{\text {cow }}
$$

Combining with saturation equation and mass conservation equation, the saturation equation of streamline model for oil-water two phases can be derived:

$$
\begin{aligned}
& \phi \frac{\partial S_{\mathrm{w}}}{\partial_{\mathrm{t}}}= \\
& \nabla \cdot\left[\lambda_{\mathrm{w}}\left(\gamma-\gamma_{\mathrm{w}}\right) \nabla D\right]-\phi \frac{\partial S_{\mathrm{w}}}{\partial_{\tau}}-\nabla \cdot\left(\frac{\lambda_{\mathrm{w}} \lambda_{\mathrm{o}}}{\lambda_{\mathrm{t}}} \nabla P_{\mathrm{cow}}\right)+q_{\mathrm{vw}}
\end{aligned}
$$


Simplified as:

$$
\frac{\partial S_{\mathrm{w}}}{\partial_{\mathrm{t}}}+\frac{\partial f_{\mathrm{w}}}{\partial_{\tau}}+\frac{1}{\phi} \nabla \overline{G_{\mathrm{w}}}=\frac{q_{\mathrm{w}}}{\phi}
$$

where $\nabla \bar{G}_{w}$ is defined as:

$$
\bar{G}_{\mathrm{w}}=-\left[\lambda_{\mathrm{w}}\left(\gamma-\gamma_{\mathrm{w}}\right) \nabla D\right]+\left(\frac{\lambda_{\mathrm{w}} \lambda_{\mathrm{o}}}{\lambda_{\mathrm{t}}} \nabla P_{\mathrm{cow}}\right)
$$

C. Numerical solution for saturation equation of streamline model. Because the derived equation is a complicated convective diffusion equation, for simplicity, solve the convection term, gravity and capillary item in a saturation equation by utilizing the technique of operator separation. The convective diffusion equation can be divided to two parts, one is a nonlinear hyperbolic equation describing the convection term, the other one is a parabolic equation describing the effects of gravity and capillary.

As the streamlines generate from the grid cell face of injection well and dissolved at the grid cell face of the production well, the field along streamlines is sourcefree.

Decoupling (8) by utilizing operator separation technique, two equations are obtained as follows:

$$
\begin{gathered}
\frac{\partial S_{\mathrm{w}}}{\partial_{\mathrm{t}}}+\frac{\partial f_{\mathrm{w}}}{\partial_{\tau}}=0 \quad S_{\mathrm{w}}(\tau, 0)=S_{\mathrm{w} 0}(\tau) \\
\frac{\partial S_{\mathrm{w}}}{\partial_{\mathrm{t}}}+\frac{1}{\phi} \nabla \bar{G}_{\mathrm{w}}=0 \quad S_{\mathrm{w}}(\tau, 0)=S_{\mathrm{w} 0}(\tau)
\end{gathered}
$$

Eq.10 is a 1D saturation equation, and can be solved by $1 \mathrm{D}$ numerical solution along streamlines (transformation of the 3D equation to $1 \mathrm{D}$ equation). The solution for (10) is assumed as $\operatorname{Sf}(t)$. Eq.11 is a saturation equation considering the effects of gravity and capillary, and can be solved only by $3 \mathrm{D}$ numerical solution. The solution for (11) is assumed as $\mathrm{H}(\mathrm{t})$. Finally, the solution at time $t_{n}\left(t_{n}=n \Delta t\right)$ is derived as:

$$
S_{\mathrm{w}}(\tau, n \Delta t)=\left[H(\Delta t) \cdot S^{f}(\Delta t)\right]^{n} S_{\mathrm{w} 0}(\tau)
$$

\subsection{Streamline Update}

For the actual development process in the oil field, well pattern and production system is not fixed. Especially for the oil filed with very long production periods, we often need to establish some methods to stimulate, such as pattern adjustment, shut-in, isolation of individual zones and water shut off, fracturing and acidizing, infilling, which will change the streamline distribution. So we have to update the streamlines immediately after those conditions to accurately represent the displacing dynamic information.

\subsection{Compare with Finite Difference Simulation}

Compare the water cut of streamline simulation and finite difference simulation, it is easy to know that the streamline simulation's result is more close to the historical data at initial stage. This is because the improvement on saturation calculation. So streamline simulation is more suitable for study on flooding.

\section{OPTIMIZATION OF FRACTURING}

\subsection{Simulation of Fractured Horizontal Wells}

The flow field of flooding unit in combined well pattern of horizontal and vertical wells is drew basing on the result of streamline simulations as Figure 1. Respectively, the situation with fractured horizontal well and the one with unfractured horizontal well are simulated. As shown in Figure 1, the fractures inflect the flow field around the middle of horizontal section. As the former study, the inflow rate is lowest in the middle of horizontal section. So the fractures improve both the productivity of horizontal well and the efficiency of the flooding unit.

\subsection{Orthogonal Experimental Design}

In flooding unit contains fractured horizontal well, the main factors affecting the sweep efficiency are distance between fractures, fracture half length and fracture conductivity. In orthogonal design experiments, influence factors are called factors, and the data points of factors

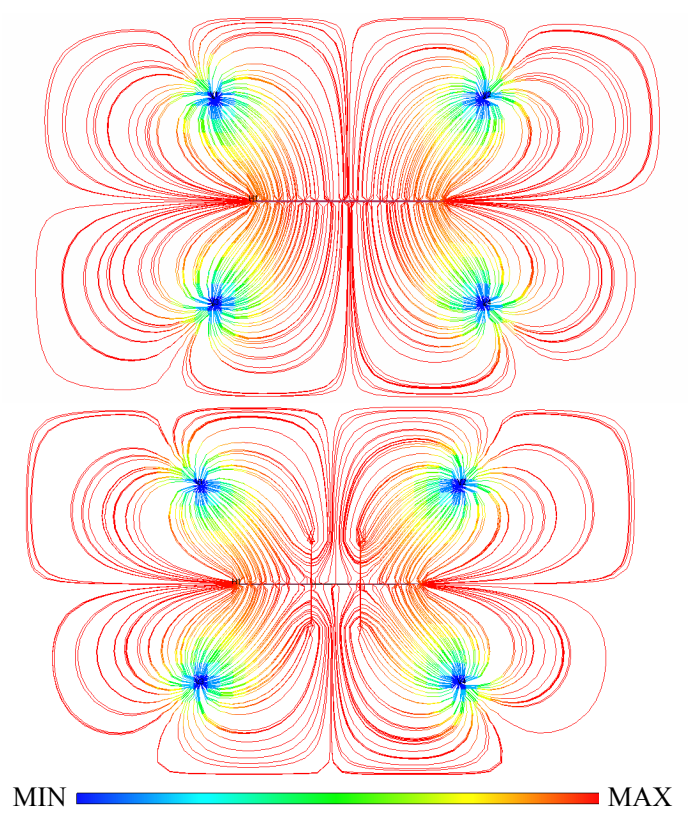

Figure 1. Streamlines representing oil saturation. 
called levels. There are three factors which effect development, so using L9 (33)-type orthogonal to arrange experiments.

Basing on the orthogonal experimental design table, orthogonal experiment is designed as Table 2.

\subsection{Simulation of Orthogonal Experiment}

Simulate projects and record the sweep efficiency when water cut is $98 \%$. The results of streamline simulation show that NO.6 project has the highest sweep efficiency with the number $88.57 \%$. But the results of simulation cannot distinguish the sequence of priority of factors. To study the impact on sweep efficiency by factors the range of factors should be analyzed.

\subsection{Analysis of Factors}

According to the size of range, the impact of factor on the size of the experimental results can be determined. In orthogonal experiment method, range is the difference between the maximum and minimum values at different levels of the same factor. The bigger range a factor has, the more it influences the size of the experimental result.

Before the analysis of the sequence of priority of factors, the experimental result should be processed as follows: 1) Sum the values of results in same level of one

Table 1. Factors and levels.

\begin{tabular}{cccc}
\hline & $\mathrm{A}$ & $\mathrm{B}$ & $\mathrm{C}$ \\
\cline { 2 - 4 } Level & $\begin{array}{c}\text { Fracture Half } \\
\text { Length }(\mathrm{m})\end{array}$ & $\begin{array}{c}\text { Fracture } \\
\text { Conductivity } \\
(\mathrm{D} \cdot \mathrm{cm})\end{array}$ & $\begin{array}{c}\text { Distance between } \\
\text { Fractures }(\mathrm{m})\end{array}$ \\
\hline 1 & 75 & 25 & 100 \\
2 & 100 & 35 & 150 \\
3 & 125 & 45 & 200 \\
\hline
\end{tabular}

Table 2. Orthogonal experiment.

\begin{tabular}{cccc}
\hline \multirow{2}{*}{$\begin{array}{c}\text { Project } \\
\text { No. }\end{array}$} & $\begin{array}{c}\text { Fracture Half } \\
\text { Length }(\mathrm{m})\end{array}$ & $\begin{array}{c}\text { Fracture } \\
\text { Conductivity }(\mathrm{D} \cdot \mathrm{cm})\end{array}$ & $\begin{array}{c}\text { Distance between } \\
\text { Fractures }(\mathrm{m})\end{array}$ \\
\cline { 2 - 4 } 1 & 75 & 25 & 100 \\
2 & 100 & 25 & 150 \\
3 & 125 & 25 & 200 \\
4 & 75 & 35 & 150 \\
5 & 100 & 35 & 200 \\
6 & 125 & 35 & 100 \\
7 & 75 & 45 & 200 \\
8 & 100 & 45 & 100 \\
\hline
\end{tabular}
9
125
45
150

factor. As there are three levels in one factor, K1, K2 and K3 are used to indicate the sums respectively. 2) Average the values of results in same level of one factor. Use k1, $\mathrm{k} 2$ and $\mathrm{k} 3$ to indicate the averages respectively. 3) Solve the size of range of each factor, and use $\mathrm{R}$ to indicate it.

According to the above rules, the ranges is calculated as Table 4. It shows, the range of factor A is biggest with

Table 3. Results of simulation.

\begin{tabular}{cc}
\hline Level & Sweep Efficiency \\
\hline 1 & 0.8837 \\
2 & 0.8493 \\
4 & 0.7684 \\
5 & 0.8808 \\
6 & 0.8076 \\
7 & 0.8857 \\
8 & 0.8680 \\
9 & 0.8635 \\
\hline
\end{tabular}

Table 4. The range of experimental result.

\begin{tabular}{|c|c|c|c|c|}
\hline & A & B & $\mathrm{C}$ & Measurement \\
\hline $\begin{array}{c}\text { Project } \\
\text { No. }\end{array}$ & $\begin{array}{c}\text { Fracture Half } \\
\text { Length (m) }\end{array}$ & $\begin{array}{c}\text { Fracture } \\
\text { Conductivity } \\
(\mathrm{D} \cdot \mathrm{cm})\end{array}$ & $\begin{array}{c}\text { Distance } \\
\text { between } \\
\text { Fractures } \\
(\mathrm{m})\end{array}$ & $\begin{array}{c}\text { Sweep } \\
\text { efficiency }\end{array}$ \\
\hline 1 & 75 & 25 & 100 & 0.8837 \\
\hline 2 & 100 & 25 & 150 & 0.8493 \\
\hline 3 & 125 & 25 & 200 & 0.7684 \\
\hline 4 & 75 & 35 & 150 & 0.8808 \\
\hline 5 & 100 & 35 & 200 & 0.8076 \\
\hline 6 & 125 & 35 & 100 & 0.8857 \\
\hline 7 & 75 & 45 & 200 & 0.8680 \\
\hline 8 & 100 & 45 & 100 & 0.8635 \\
\hline 9 & 125 & 45 & 150 & 0.7823 \\
\hline K1 & 2.632 & 2.501 & 2.633 & \\
\hline $\mathrm{K} 2$ & 2.521 & 2.574 & 2.512 & \\
\hline K3 & 1.654 & 2.514 & 2.444 & \\
\hline $\mathrm{k} 1$ & 0.877 & 0.834 & 0.878 & \\
\hline $\mathrm{k} 2$ & 0.840 & 0.858 & 0.837 & \\
\hline
\end{tabular}




\begin{tabular}{cccc}
\hline $\mathrm{k} 3$ & 0.551 & 0.838 & 0.815 \\
$\mathrm{R}$ & 0.326 & 0.024 & 0.063 \\
\hline
\end{tabular}

[1] Grinestaff, G.H. and Caffrey, D.J. (2000) Waterflood management: A case study of the northwest fault block area of Prudhoe Bay, Alaska, using streamline simulation and traditional waterflood analysis. Paper SPE 63152 Presented at the 2000 SPE Annual Technical Conference and Exhibition, Dallas, 1-4 October.

ing the sweep efficiency is the fracture half length, followed by distance between fractures and the weakest which is fracture conductivity. The sequence of priority of factors is as follow: $\mathrm{A}>\mathrm{B}>\mathrm{C}$.

\section{CONCLUSIONS}

In this paper, the streamline model considering fractured horizontal well is derived. The streamlines provide us with a clear picture of flow field of flooding unit in combined well pattern of horizontal and vertical wells.

The streamline simulation results indicate that the fracture plays an important role in enhancing sweep efficiency and stimulation.

The sequence of priority of distance between fractures, fracture length and fracture conductivity has been determined.

\section{REFERENCES}

[2] Chakravarty, A., Liu, D.B. and Meddaugh, S. (2000) Application of 3D streamline methodology in the Saladin reservoir and other studies. Paper SPE 63154 Presented at the 2000 SPE Annual Technical Conference and Exhibition, Dallas, 1-4 October.

[3] Lolomari, T., Bratvedt, K., Crane, M., Milliken, W.J. and Tyrie, J.J. (2000) The use of streamline simulation in reservoir management: Methodology and case studies. Paper SPE 63157 Presented at the 2000 SPE Annual Technical Conference and Exhibition, Dallas, 1-4 October.

[4] Grinestaff, G.H. (2000) Waterflood pattern allocations: Quantifying the injector to producer relationship with streamline simulation. Paper SPE 54616 Presented at the 2000 SPE Western Regional Meeting, Anchorage, 26-28 May.

[5] Thiele, M.R. (2001) Streamline Simulation. Paper Presented at the 6th International Forum on Reservoir Simulation, Schloss Fuschl, 3-7 September. 